\title{
Evaluating the level of satisfaction of patients utilizing first-level health facilities as a function of health system performance rating in the province of Elazig, Turkey
}

\author{
This article was published in the following Dove Press journal: \\ Patient Preference and Adherence \\ 28 October 2014 \\ Number of times this article has been viewed
}

\author{
Aliye Bulut \\ A Ferdane Oguzoncul \\ Department of Public Health, Faculty \\ of Medicine, Firat University, Elazig, \\ Turkey
}

Purpose: This study was conducted to determine the level of satisfaction of patients utilizing first-level health care facilities as a function of health system performance rating in Elazig province of Turkey.

Methods: The study was conducted between December 2013 and March 2014 at the family health centers in the Elazig province center. For collecting the data in the cross-sectional study conducted with 1,290 patients, personal data form for patients and the Turkish version of European Patients Evaluate General/Family Practice scale was used.

Results: Of the patients who participated in the study, 54.3\% were female. According to the general average scores received by the patients from European Patients Evaluate General/Family Practice-TR Patient Satisfaction Survey questions, average scores of male patients were found to be higher than those of female patients. Scores of the divorced and widow patients were higher compared to other groups, but this was not statistically significant. Average scores of the patients whose educational status is secondary school were higher compared to other groups. Scores of the patients with children were higher compared to those without children. Scores of the patients whose occupation was farming were higher compared to the other groups of occupation. Scores of the patients whose income was TL 1,001-2,500 were found to be higher compared to other patients. Scores of the patients who stated that they never had difficulty in access were higher compared to others, but this was not statistically significant. Average scores of the patients who had chronic diseases and patients who stated to have physical handicap were higher compared to those who did not have chronic disease and physical handicap, but these differences were not found to be statistically significant, either.

Conclusion: There is a statistically significant difference between the patients' demographic characteristics (sex, educational status, occupation, and income status) and their levels of satisfaction with the family medicine practice.

Keywords: patient satisfaction, primary care, EUROPEP

\section{Introduction}

According to the definition by the World Health Organization, health is the state of being well in spiritual, physical, and social terms. Health of the individual and the society is associated with three main factors, ie, environmental, behavioral, and medicinal. Health services mean the whole range of activities concerning diagnosis, treatment, and rehabilitation of the diseases as well as prevention of the diseases and improvement of health level of the society and the individual. ${ }^{1}$
Correspondence: Aliye Bulut

Department of Public Health,

Faculty of Medicine, Firat University,

23I I 9 Elazig, Turkey

Tel +904248173113

Email aliyedemirok@yahoo.com 
Health services may be categorized into three groups, which are preventive, therapeutic, and rehabilitative services. $^{2}$

1. Protective health services: Services provided for protecting the health and preventing the diseases fall within this group. They are considered in three levels:

a. Primary protection

b. Secondary protection

c. Tertiary protection ${ }^{2}$

2. Therapeutic health services: The aim of these services is to heal the persons who have acquired disease. They are considered in three steps:

a. First-step health services: The health system that can reach the individual and the families within the society as a whole, solve health problems of the community, protect the health, and provide home and outpatient therapy services. ${ }^{3}$

b. Second-step health services: The services provided for diagnosis and inpatient therapy of the patients.

c. Third-step health services: Health services provided for the diseases requiring advanced examination and special therapy. ${ }^{3}$

3. Rehabilitative health services: They cover all the activities carried out to enable those who have been physically or spiritually disabled to live without dependency on others. ${ }^{2}$

In the provision of health services, the term "quality" may be defined as "diagnosis, therapy and care services in conformity with the standards in the internationally applicable indicators as well as fully meeting the expectations and needs of the patients in all of the service processes". ${ }^{3}$

A medical doctor who provides first-step health service on individual, integrated, and continuous basis, who has received specialty education in this regard, is a "Family Physician" with the designation adopted by the Ministry of Health in our country. In several countries, a first-step physician who has received postgraduate training according to the international standards is designated as a "General Practitioner". A family physician whom a patient encounters first within the system should have qualifications such that he will be able to judge whether the patient can be treated at the first step and whether his/her referral to other branch specialists and/or hospitals will be required, apply actual screening, protect, provide therapy and follow-up protocols, and carry out multidisciplinary researches required by the first step. ${ }^{4}$

\section{Patient satisfaction}

Patient satisfaction is defined as "the basic criterion giving information on to what extent the values and expectations of the patient are met, and showing quality of the care provided by the main authority to the patients". ${ }^{5}$ Patient satisfaction is a multidimensional concept involving provision of the service, interaction of the patient and the service providers, existence and continuity of the service, and competency and communication characteristics of the service providers. Hence, patient satisfaction is regarded as an outcome of the health services and generally an indicator of the care quality. ${ }^{6}$ Determination of the patient satisfaction in health services may contribute to revealing the strengths and weaknesses of the health institutions, may be important in terms of competition of the service provider institutions with each other, and may increase compliance by the patients who are satisfied with the services and advices of physicians and other health professionals. $^{7}$

\section{European Patients Evaluate General/ Family Practice: an international standardized scale to evaluate the family medicine}

European Patients Evaluate General/Family Practice (EUROPEP) scale was developed to be able to perform an international comparison of the outcomes of the family medicine in Europe. Such a comparison among the countries having different health systems may be helpful for the makers of health policies in developing the First Step systems in Europe. ${ }^{8}$ The EUROPEP scale, which provides feedback to the physicians in the countries it is applied and which enables comparison of itself with national and international standards, is an internationally accepted scale, for which validity and reliability studies have been conducted in 16 European countries. Validity and reliability study of the EUROPEP-TR Scale was conducted by Akturk et al in 2002. ${ }^{1}$

In light of these studies, we aimed to determine the level of satisfaction of the patients utilizing first-level health facilities and find out whether the level of satisfaction of patients regarding quality of health services provided is a function of health system performance rating in the Elazig province of Turkey.

\section{Materials and methods}

This study, which has cross-sectional, descriptive, and analytic characteristics, was conducted at the family health centers in Elazig province center between December 2013 and March 2014. The study universe consisted of the first 15 patients aged 18 and more who have applied to 86 family physicians affiliated to 30 family medicine units registered in the Elazig province center and who have accepted 
participating in the study. For collecting the data in the study conducted with 1,290 patients, personal data form for patients and the Turkish version of the EUROPEP scale was used.

The EUROPEP scale providing feedback to the physician in the countries it is applied and allowing him/her to compare himself/herself with national and international norms is arranged in the style of the 5-point Likert scale rated from 1 to 5 (from very bad to very good), and the first 16 questions measure the clinic behavior while the remainder questions measure the service organization.

Oral consents of the patients who were willing to participate in the study were taken, the requirements of having applied at least once during the last 1 year to the physician they were applying at that time and being acquainted with the physician were sought for, and it was ensured that they answer the questions. The demographic data in the survey applied were transferred to the statistics program. Statistical significance level $(P)$ was shown together with the relevant tests, and the values with $P<0.05$ were considered statistically significant.

\section{Hypotheses of the study}

This study addressed the primary topics such as evaluation of demographic characteristics of the individuals applying to the family physicians or family health centers in the Elazig province of Turkey, their level of knowledge about family medicine, evaluation of the environment where the service is provided, the health service provided, and the staff and strived to evaluate the level of satisfaction with the family medicine practice. It was examined whether the conclusions derived from the field research validated the following hypotheses.

Hypothesis 1 (H1)

$\mathrm{H}_{0}$ : There is no statistically significant difference between demographic characteristics (sex, marital status, age, educational status, occupation, and income status) of the individuals and the level of satisfaction with the family medicine practice.

$\mathrm{H}$ : There is a statistically significant difference between demographic characteristics (sex, marital status, age, educational status, occupation, and income status) of the individuals and the level of satisfaction with the family medicine practice.

\section{Limitations of the study}

This study was conducted on the family medicine practice that is offered as a health model. Several limitations were imposed since applying the study throughout Elazig and to all individuals receiving service from family physicians was difficult in terms of both time and cost. For this purpose, the study was conducted only on those individuals who agreed to participate in the Elazig province center (excluding counties and towns). Surveys of the individuals who were illiterate or who had difficulty in understanding the questions were completed through reading of the questions by the researcher. Surveys completed wrongly or deficiently were excluded from evaluation since they could reduce reliability of the study and result in attaining inaccurate results and conclusions.

\section{Criteria for exclusion from the study}

Not finding the patient's statement reliable (dementia, psychosis, mental retardation, hearing handicap that will hinder communication, etc) was considered as a criteria for exclusion.

\section{Results}

\section{Demographic data}

Distribution of the patients according to their sociodemographic characteristics is given in Table 1. A total

Table I Distribution of patients by their socio-demographic characteristics

\begin{tabular}{|c|c|c|c|}
\hline & & $\begin{array}{l}\text { Number of } \\
\text { individuals }\end{array}$ & $\begin{array}{l}\text { Percentage } \\
\text { (\%) }\end{array}$ \\
\hline \multirow[t]{2}{*}{ Sex } & Male & 589 & 45.7 \\
\hline & Female & 701 & 54.3 \\
\hline \multirow[t]{3}{*}{ Marital status } & Married & 834 & 64.7 \\
\hline & Single & 375 & 29.1 \\
\hline & $\begin{array}{l}\text { Other } \\
\text { (divorced, widow) }\end{array}$ & 81 & 6.2 \\
\hline \multirow[t]{3}{*}{ Age group } & 18-44 years & 950 & 73.6 \\
\hline & $45-64$ years & 275 & 21.3 \\
\hline & $\geq 65$ years & 65 & 5.1 \\
\hline Number of children & No children & 74 & 8.2 \\
\hline (among married and & I child & 161 & 17.8 \\
\hline non-single patients) & $\geq 2$ children & 669 & 74 \\
\hline \multirow[t]{6}{*}{ Educational status } & Illiterate & 60 & 4.8 \\
\hline & Literate & 76 & 5.9 \\
\hline & $\begin{array}{l}\text { Primary school } \\
\text { graduate }\end{array}$ & 247 & 19.1 \\
\hline & $\begin{array}{l}\text { Secondary school } \\
\text { graduate }\end{array}$ & 201 & 15.6 \\
\hline & High school graduate & 392 & 30.4 \\
\hline & University graduate & 314 & 24.2 \\
\hline \multirow[t]{7}{*}{ Occupation } & Housewife & 445 & 34.5 \\
\hline & Civil servant & 258 & 20.0 \\
\hline & Worker & 122 & 9.5 \\
\hline & Retired & 50 & 3.9 \\
\hline & Student & 186 & 14.4 \\
\hline & Farmer & 57 & 4.4 \\
\hline & Freelancer & 172 & 13.3 \\
\hline
\end{tabular}


of 1,290 patients participated in the study. Of the patients who participated in the study, 54.3\% (701) were female. Average age of the patients who participated in the study was $36.91 \pm 14.04$ ( minimum $=18$, maximum $=84$ ).

The average monthly household income of the patients who participated in the study was TL 1,835.94 $\pm 1,152.44$, and their income ranged from TL 300 to 10,$000 ; 6.6 \%$ (86) of the individuals in all groups were determined to have a household income of TL $0-500$ and $30.9 \%$ (398) stated to have an income of TL 501-1,000. Those whose income was TL 2,500 and more were $16.3 \%$ (210).

It was observed that $43.6 \%$ (562) of the patients did not have any difficulty in accessing the health center, $18.2 \%$ (235) rarely had difficulty, and 29.2\% (377) occasionally had difficulty.

When the reasons of the 728 patients who had difficulty accessing the health center were examined, it was determined that $47.1 \%$ (343) had difficulty due to long queues and $16.1 \%$ (117) had difficulty because of the difficulty in getting appointment.

When the reasons of the 1,290 patients who participated in the study for applying to the family health centers were examined, it was observed that $26.7 \%$ (344) patients applied due to a new complaint and $24.7 \%$ (319) applied for getting prescription.

When the disease frequency was examined, $72.0 \%$ of the 1,290 patients did not have a known chronic disease. Among $361(28 \%)$ patients who had chronic disease, 141 (10.9\%) had hypertension, 102 (7.9\%) had diabetes, and 47 (3.6\%) were cardiac patients. Of the 1,290 patients who participated in the study, $96.5 \%(1,245)$ did not have a known physical handicap.

\section{Data on EUROPEP}

Percentage distribution of the scores given by the patients to satisfaction survey question is presented in Table 2 . The highest and lowest scored questions in the survey were examined. The highest scored questions were "he/she keeps your records and information secret", "he/she listens to you", and "he/ she does his/her job exactly". The lowest scored questions were "you can access your doctor and the health center by telephone" and "the time you spend in the waiting room".

Distribution of the general average scores the patients have received from EUROPEP-TR Patient Satisfaction Survey by their several characteristics is given in Table 3.

Regression analysis of the EUROPEP-TR satisfaction survey scores by the variables such as the patient's age, sex, marital status, educational status, having children, occupation, income, difficulty in accessing, chronic disease, and physical handicap state is shown in Table $4\left(R^{2}=0.044\right.$, standard error $=0.76$, analysis of variance $[$ ANOVA] $F=5.62$, $P<0.001)$. Accordingly, we can say that the level of satisfaction of the patients who are male, who are a secondary school graduate, who have children, and whose income level is between TL 1,001 and 2,500 is higher (Table 4).

When the EUROPEP-TR Patient Satisfaction Survey general average scores were evaluated by age groups of the patients, no significant difference was found between the age groups (ANOVA $F=1.280, P=0.27$ ). When the EUROPEP-TR Patient Satisfaction Survey questions were evaluated, the score received by the patients aged 65 and more for the question "Assistance by non-doctor personnel" was higher compared to the other age groups, and this difference was statistically significant (ANOVA $F=4.284, P=0.01$ ).

When the average scores received by the patients from the EUROPEP-TR Patient Satisfaction Survey questions were evaluated by their sexes, there was a significant difference in all questions other than the questions "He/she keeps your records and information secret" and "He/she examines you". Average scores of male patients were found to be higher compared to female patients $(P<0.05)$.

When the average scores received by the patients from the EUROPEP-TR Patient Satisfaction Survey questions were evaluated by their marital statuses, no significant difference was found in terms of marital status (ANOVA $F=2.487$, $P=0.08)$. When the EUROPEP-TR Patient Satisfaction Survey questions were examined, the score received from the questions "He/she listens to you" (ANOVA $F=3.891$, $P=0.02$ ) and "He/she examines you" (ANOVA $F=3.788$, $P=0.02$ ) was significantly high in the married patients, and the scores received from the questions " $\mathrm{He} / \mathrm{she}$ assists you to overcome the emotional problems associated with your health condition" (ANOVA $F=4.483, P=0.01$ ), "He/she knows what he/she has done and told in the previous visits" (ANOVA $F=5.100, P=0.006)$, "You can access your doctor by telephone" (ANOVA $F=3.720, P=0.02$ ), and "The time you spend in the waiting room" (ANOVA $F=3.397, P=0.03$ ) by the divorced and widow patients were significantly high.

When the average scores received by the patients from the EUROPEP-TR Patient Satisfaction Survey questions by their educational statuses were evaluated, the patients whose educational status is secondary school received higher score from the questions "He/she makes it easy for you to tell your problems to him/her", "He/she listens to you", "He/ she does his/her job exactly", "Services he/she provides for your protection from diseases (health screening, health 
Table 2 Percentage distribution of the scores given to EUROPEP-TR Questions

\begin{tabular}{|c|c|c|c|c|c|c|}
\hline \multirow[t]{2}{*}{ Patient satisfaction survey } & \multicolumn{5}{|l|}{ n (\%) } & \multirow[t]{2}{*}{ N/A } \\
\hline & $\mathbf{I}$ & 2 & 3 & 4 & 5 & \\
\hline He/she makes you feel you have sufficient time during visits & $60(4.7)$ & $86(6.7)$ & $154(11.9)$ & $298(23.1)$ & $685(53.1)$ & $7(0.5)$ \\
\hline $\mathrm{He} / \mathrm{she}$ takes care of your special condition & $46(3.6)$ & $84(6.5)$ & $140(10.9)$ & $334(25.9)$ & $683(52.9)$ & $3(0.2)$ \\
\hline He/she makes it easy for you to tell your problems to him/her & $26(2.0)$ & $73(5.7)$ & $137(10.6)$ & $326(25.3)$ & $723(56.0)$ & $5(0.4)$ \\
\hline $\mathrm{He} / \mathrm{she}$ includes you in the decisions about your medical care & $47(3.6)$ & $85(6.6)$ & $133(10.3)$ & $341(26.4)$ & $674(52.2)$ & $10(0.8)$ \\
\hline $\mathrm{He} /$ she listens to you & $27(2.1)$ & $58(4.5)$ & $100(7.8)$ & $291(22.6)$ & $810(62.8)$ & $4(0.3)$ \\
\hline $\mathrm{He} / \mathrm{she}$ keeps your records and information secret & $21(1.6)$ & $42(3.3)$ & $80(6.2)$ & $263(20.4)$ & $882(68.4)$ & $2(0.2)$ \\
\hline He/she remedies your complaints soon & $39(3.0)$ & $88(6.8)$ & $140(10.9)$ & $352(27.3)$ & $668(51.8)$ & $3(0.2)$ \\
\hline $\begin{array}{l}\text { He/she assists you to feel so well that you can meet your } \\
\text { daily needs }\end{array}$ & $33(2.6)$ & $75(5.8)$ & $155(12.0)$ & $352(27.3)$ & $670(51.9)$ & $5(0.4)$ \\
\hline $\mathrm{He} / \mathrm{she}$ does his/her job exactly & $33(2.6)$ & $5 \mathrm{I}(4.0)$ & $109(8.4)$ & $315(24.4)$ & $780(60.5)$ & $2(0.2)$ \\
\hline He/she examines you & $23(1.8)$ & $54(4.2)$ & $102(7.9)$ & $337(26.1)$ & $770(59.7)$ & $4(0.3)$ \\
\hline $\begin{array}{l}\text { Services he/she provides for your protection from diseases } \\
\text { (health screening, health check, vaccination, etc) }\end{array}$ & $32(2.5)$ & $48(3.7)$ & III (8.6) & $317(24.6)$ & $779(60.4)$ & $3(0.2)$ \\
\hline $\mathrm{He} / \mathrm{she}$ explains purposes of the tests and therapies & $31(2.4)$ & $68(5.3)$ & $124(9.6)$ & $305(23.6)$ & $758(58.8)$ & $4(0.3)$ \\
\hline $\begin{array}{l}\text { He/she gives the information you want about your complaints } \\
\text { or disease }\end{array}$ & $26(2.0)$ & $55(4.3)$ & $114(8.8)$ & $330(25.6)$ & $760(58.9)$ & $5(0.4)$ \\
\hline $\begin{array}{l}\text { He/she assists you to overcome the emotional problems associated } \\
\text { with your health condition }\end{array}$ & $66(5.1)$ & $83(6.4)$ & $148(\mid 1.5)$ & $330(25.6)$ & $662(5 \mid .3)$ & $\mathrm{I}(0.1)$ \\
\hline $\begin{array}{l}\text { He/she assists you to perceive importance of complying with his/her } \\
\text { advices }\end{array}$ & $30(2.3)$ & $75(5.8)$ & $145(\mid 1.2)$ & $326(25.3)$ & $707(54.8)$ & $7(0.5)$ \\
\hline He/she knows what he/she has done and told in the previous visits & $60(4.7)$ & $94(7.3)$ & $136(10.5)$ & $320(24.8)$ & $677(52.5)$ & $3(0.2)$ \\
\hline $\begin{array}{l}\text { He/she prepares you for what you should expect from } \\
\text { referral to specialist or hospital }\end{array}$ & $27(2.1)$ & $96(7.4)$ & $147(11.4)$ & $324(25.1)$ & $684(53.0)$ & $12(0.9)$ \\
\hline Assistance by non-doctor personnel & $46(3.6)$ & $6 \mathrm{I}(4.7)$ & $128(9.9)$ & $320(24.8)$ & $73 \mid(56.7)$ & $4(0.3)$ \\
\hline You can get appointment for the times suitable for you & $53(4.1)$ & $76(5.9)$ & $115(8.9)$ & $358(27.8)$ & $682(52.9)$ & $6(0.5)$ \\
\hline You can access the health center by telephone & $71(5.5)$ & $66(5.1)$ & $105(8.1)$ & $334(25.9)$ & $698(54.1)$ & $16(1.2)$ \\
\hline You can access your doctor by telephone & $134(10.4)$ & $72(5.6)$ & $129(10.0)$ & $323(25.0)$ & $613(47.5)$ & $19(1.5)$ \\
\hline The time you spend in the waiting room & $108(8.4)$ & $84(6.5)$ & $197(15.3)$ & $342(26.5)$ & $549(42.6)$ & $10(0.8)$ \\
\hline $\mathrm{He} /$ she provides quick service for urgent health problems & $46(3.6)$ & $67(5.2)$ & $127(9.8)$ & $35 I(27.2)$ & $692(53.6)$ & $7(0.5)$ \\
\hline
\end{tabular}

Abbreviations: EUROPEP, European Patients Evaluate General/Family Practice; n, number of individuals who scored; N/A, not applicable.

check, vaccination, etc)", "He/she explains purposes of the tests and therapies", "He/she gives the information you want about your complaints or disease", "He/she assists you to perceive importance of complying with his/her advices", "He/she knows what he/she has done and told in the previous visits", "He/she prepares you for what you should expect from referral to specialist or hospital", "Assistance by nondoctor personnel", and "He/she provides quick service for urgent health problems", and the patients who stated to be literate received higher score from the question "The time you spend in the waiting room", and this difference was statistically significant $(P<0.05)$.

When the average scores received by the patients from the EUROPEP-TR Patient Satisfaction Survey questions were evaluated by the state of having children, the average score received by the patients who stated to have children from the questions "He/she makes you feel you have sufficient time during visits", "He/she takes care of your special condition", "He/she makes it easy for you to tell your problems to him/her", "He/she remedies your complaints soon", "He/she assists you to overcome the emotional problems associated with your health condition", "He/she prepares you for what you should expect from referral to specialist or hospital", "Assistance by non-doctor personnel", "You can get appointment for the times suitable for you", "You can access your doctor by telephone", "The time you spend in the waiting room", and "He/she provides quick service for urgent health problems" was higher, and this difference was statistically significant $(P<0.05)$.

When the average scores received by the patients from the EUROPEP-TR Patient Satisfaction Survey questions were evaluated by their occupations, the average score received by the patients whose occupation is farming from the questions "He/she makes you feel you have sufficient time during visits", "He/she includes you in the decisions about your medical care", "He/she does his/her job exactly", "He/ she gives the information you want about your complaints or disease", "He/she assists you to overcome the emotional 
Table 3 Comparison of EUROPEP-TR survey general average scores of the patients based on the demographic characteristics

\begin{tabular}{|c|c|c|c|c|c|}
\hline Characteristics & & Number (n) & Average \pm SD & $\boldsymbol{F}$ & $P$-value \\
\hline \multirow[t]{3}{*}{ Age } & 18-44 years & 903 & $4.26 \pm 0.77$ & 1.280 & 0.278 \\
\hline & $45-64$ years & 269 & $4.20 \pm 0.77$ & & \\
\hline & $\geq 65$ years & 62 & $4.37 \pm 0.77$ & & \\
\hline \multirow[t]{2}{*}{ Sex } & Male & 574 & $4.35 \pm 0.71$ & - & $<0.001$ \\
\hline & Female & 660 & $4 .|6 \pm 0.8|$ & & \\
\hline \multirow[t]{3}{*}{ Marital status } & Married & 803 & $4.28 \pm 0.74$ & 2.487 & 0.08 \\
\hline & Single & 352 & $4.17 \pm 0.83$ & & \\
\hline & Other* & 79 & $4.29 \pm 0.76$ & & \\
\hline \multirow[t]{6}{*}{ Educational status } & Illiterate & 57 & $4.16 \pm 0.76$ & 2.995 & 0.01 \\
\hline & Literate & 72 & $4.23 \pm 0.83$ & & \\
\hline & Primary school & 232 & $4.29 \pm 0.75$ & & \\
\hline & Secondary school & 197 & $4.4 I \pm 0.64$ & & \\
\hline & High school & 373 & $4.25 \pm 0.75$ & & \\
\hline & University & 303 & $4.15 \pm 0.86$ & & \\
\hline \multirow[t]{2}{*}{ Children } & No & 423 & $4.18 \pm 0.79$ & - & 0.01 \\
\hline & Yes & 811 & $4.29 \pm 0.76$ & & \\
\hline \multirow[t]{7}{*}{ Occupation } & Civil servant & 248 & $4.18 \pm 0.82$ & 3.797 & 0.001 \\
\hline & Worker & 119 & $4.39 \pm 0.73$ & & \\
\hline & Farmer & 56 & $4.50 \pm 0.54$ & & \\
\hline & Freelancer & 166 & $4.36 \pm 0.67$ & & \\
\hline & Housewife & 422 & $4.24 \pm 0.75$ & & \\
\hline & Student & 174 & $4.09 \pm 0.87$ & & \\
\hline & Retired & 49 & $4.30 \pm 0.80$ & & \\
\hline \multirow[t]{4}{*}{ Income status } & $0-500$ & 78 & $3.92 \pm 0.95$ & 8.940 & $<0.001$ \\
\hline & $50 \mathrm{I}-\mathrm{I}, 000$ & 378 & $4.26 \pm 0.74$ & & \\
\hline & $\mathrm{I}, 00 \mathrm{I}-2,500$ & 578 & $4.34 \pm 0.72$ & & \\
\hline & $\geq 2,50 \mathrm{I}$ & 200 & $4.13 \pm 0.83$ & & \\
\hline \multirow[t]{5}{*}{ Difficulty in access } & Never & 534 & $4.3 I \pm 0.74$ & 0.449 & 0.71 \\
\hline & Rarely & 221 & $4.17 \pm 0.81$ & & \\
\hline & Occasionally & 365 & $4.23 \pm 0.79$ & & \\
\hline & Usually & 70 & $4.20 \pm 0.69$ & & \\
\hline & Always & 44 & $4.12 \pm 0.87$ & & \\
\hline \multirow[t]{2}{*}{ Chronic disease } & Yes & 349 & $4.29 \pm 0.78$ & - & 0.31 \\
\hline & No & 885 & $4.24 \pm 0.77$ & & \\
\hline \multirow[t]{2}{*}{ Physical handicap } & Yes & 45 & $4.34 \pm 0.65$ & - & 0.42 \\
\hline & No & 1,189 & $4.25 \pm 0.77$ & & \\
\hline \multirow[t]{7}{*}{ Reason of application } & New complaint & 333 & $4.27 \pm 0.80$ & 0.966 & 0.44 \\
\hline & Chronic & 72 & $4.15 \pm 0.88$ & & \\
\hline & Checkup & 248 & $4.23 \pm 0.74$ & & \\
\hline & Protective & 129 & $4.26 \pm 0.71$ & & \\
\hline & Prescription & 302 & $4.30 \pm 0.77$ & & \\
\hline & Medication report & 57 & $4.31 \pm 0.68$ & & \\
\hline & Other & 93 & $4 .|3 \pm 0.8|$ & & \\
\hline
\end{tabular}

Notes: $* P<0.05$. Student's t-test and analysis of variance.

Abbreviations: EUROPEP, European Patients Evaluate General/Family Practice; n, number of individuals who scored; SD, standard deviation.

problems associated with your health condition", "He/she assists you to perceive importance of complying with his/her advices", "He/she knows what he/she has done and told in the previous visits", "He/she prepares you for what you should expect from referral to specialist or hospital", "Assistance by non-doctor personnel", "You can get appointment for the times suitable for you", "You can access the health center by telephone", "You can access your doctor by telephone", and "He/she provides quick service for urgent health problems" was higher, and this difference was statistically significant $(P<0.05)$.

When the average scores received by the patients from the EUROPEP-TR Patient Satisfaction Survey questions were evaluated by their state of having difficulty in accessing the 
Table 4 Table of regression analysis of the EUROPEP-TR satisfaction survey general average scores by the determined variables

\begin{tabular}{|c|c|c|c|c|c|}
\hline \multicolumn{6}{|l|}{ Coefficients } \\
\hline \multirow[t]{2}{*}{ Variables } & \multicolumn{2}{|c|}{ Non-standardized coefficients } & \multirow{2}{*}{$\begin{array}{l}\text { Standard coefficients } \\
\text { Beta }\end{array}$} & \multirow[t]{2}{*}{$\boldsymbol{t}$} & \multirow[t]{2}{*}{$P$-value } \\
\hline & B & Standard error & & & \\
\hline (Constant) & 4.929 & 0.173 & & 28.492 & 0.000 \\
\hline Age & -0.059 & 0.108 & -0.017 & -0.550 & 0.583 \\
\hline Sex & -0.170 & 0.045 & -0.110 & -3.754 & 0.000 \\
\hline Marital status & -0.039 & 0.094 & -0.012 & -0.414 & 0.679 \\
\hline Educational status & -0.178 & 0.060 & -0.084 & -2.987 & 0.003 \\
\hline Children & -0.100 & 0.048 & -0.061 & -2.103 & 0.036 \\
\hline Occupation & -0.083 & 0.067 & -0.037 & -1.252 & 0.211 \\
\hline Income & -0.151 & 0.044 & -0.097 & -3.437 & 0.001 \\
\hline Difficulty in access & -0.139 & 0.044 & -0.089 & -3.142 & 0.002 \\
\hline Chronic disease & -0.006 & 0.052 & -0.003 & -0.109 & 0.913 \\
\hline Physical handicap & -0.072 & 0.119 & -0.017 & -0.600 & 0.549 \\
\hline
\end{tabular}

Abbreviation: EUROPEP, European Patients Evaluate General/Family Practice.

health institution, no significant difference was determined (ANOVA $F=0.449, P=0.71$ ). When the EUROPEP-TR Patient Satisfaction Survey questions were examined, the average score received by the patients who stated to usually have difficulty in accessing the hospital from the question "He/she assists you to overcome the emotional problems associated with your health condition" was higher, and this difference was statistically significant (ANOVA $F=2.791$, $P=0.04)$.

When the average scores received by the patients from the EUROPEP-TR Patient Satisfaction Survey questions were evaluated by their state of having chronic disease, no significant difference was determined $(t=-1.006, P=0.31)$. When the EUROPEP-TR Patient Satisfaction Survey questions were considered, the average scores received by the patients who stated not to have any chronic disease from the questions " $\mathrm{He} /$ she assists you to overcome the emotional problems associated with your health condition" ( $t=-2.097, P=0.03$ ), "He/ she assists you to perceive importance of complying with his/ her advices" $(t=-2.693, P=0.007)$, "Assistance by non-doctor personnel" ( $t=-2.851, P=0.004)$, and "The time you spend in the waiting room" ( $t=-2.814, P=0.005)$ was higher, and this difference was statistically significant.

\section{Discussion}

Ages of the patients who participated in our study ranged between 18 and 84 years. While the average age of our group was 36 years, the median value in another study conducted in regard to EUROPEP was 518, and it was 50 years in the study of Wensing et al. ${ }^{9}$ When the EUROPEP-TR Patient Satisfaction Survey general average scores were evaluated by age groups of the patients, no significant difference was found between the age groups $(P>0.05)$. No correlation was found between age and the level of satisfaction in the study of Uz et al. ${ }^{10}$

Of the patients who participated in our study, $54.3 \%$ were female. In the study by Besparmak and Sevig, 95.6\% were female. ${ }^{11}$ When the studies done abroad were considered, among those applying to first step, the rate of female patients was similarly found to be high. ${ }^{12}$ This might be the result of the other protective health services such as pregnant follow-up, child follow-up, vaccination, and family planning, which are mainly utilized by women. Average scores of male patients were found to be higher compared to female patients $(P<0.05)$. There are studies that have found that general satisfaction degrees of male students are higher. ${ }^{13}$

While 64.7 of the patients who participated in our study were married, this rate was $76.2 \%$ in the study of Deveci et $\mathrm{al}^{14}$ and $45.7 \%$ in another study. ${ }^{12}$ When the average scores received by the patients from the EUROPEP-TR Patient Satisfaction Survey questions were evaluated by their marital statuses, no significant difference was found in terms of marital status $(P>0.05)$. In the study conducted by Unalan et al, they found that satisfaction levels of the married patients were significantly higher. ${ }^{15}$

Of the participants of our study, $29.8 \%$ were found to have received education at the level of primary school or below (literate, illiterate), and $24.2 \%$ were found to be university graduates. In the EUROPEP study of Pearsman et $\mathrm{a}^{16}$ education level of $21.3 \%$ was primary school or below. Average scores of the patients whose educational status was secondary school were higher compared to the other groups $(P=0.01)$. This may be due the facts that (1) expectations of the university graduates are higher, and hence, satisfying them is more difficult, (2) persons whose educational level is low are more contented, and (3) usually during the survey study 
conducted by face-to-face interview technique, the patients whose educational level is low have given high scores since they abstained. In their study, Tukel et $\mathrm{al}^{17}$ determined that university graduates had significantly lower satisfaction with the attitudes and behaviors of doctors against them compared to the primary and secondary school graduates.

In our study, among 904 married, divorced, and widow patients, it was determined that $8.2 \%$ did not have children, $17.8 \%$ had one child, and $74 \%$ had more than one child. In a study conducted in Edirne, it was determined that $5.2 \%$ of the married, divorced, and widow patients did not have children, $23 \%$ had one child, and $71.8 \%$ had more than one child. ${ }^{18}$ When the relationship between the patient's state of having children and their satisfaction degrees were examined, scores of the patients with children were higher compared to those without children $(P=0.01)$.

While $34.5 \%$ of the individuals in our study were housewives and 20\% were civil servants, 91.3\% were housewives in the study of Pala. ${ }^{19}$ In the study conducted by Senol et al in 2010 in Kayseri, it was determined that the elderly, female patients and the illiterate people utilized the health services significantly more, and when considered in terms of occupations, the housewives and retired people applied to health centers more frequently like in our study. ${ }^{20}$ The greater number of applications to the first step by the housewives may be due to the fact that women make more application since men are at work during the business hours and that the children are taken to the doctor by mothers. Scores of the patients whose occupation was farming were higher compared to other groups of occupation $(P<0.05)$.

Monthly household income of the 1,290 patients who participated in the study was TL 1,835.94 $\pm 1,152.44$. When the average scores received by the patients from the EUROPEP-TR Patient Satisfaction Survey questions were evaluated, average scores of the patients were different in all questions other than the question "You can access the health center by telephone". In general, average scores of the patients whose income status was TL 1,001-2,500 were higher $(P<0.05)$. In the study conducted by Ercan et al they found an inverse significant relationship between educational and income level, ${ }^{21}$ whereas in the study of Erdem et al they stated that there was no relationship between the income level and patient satisfaction. ${ }^{13}$

In our study, we determined that $43.6 \%$ of the patients could conveniently apply to family physicians. This may be the result of the fact that family health centers became easily accessible upon initiation of the family medicine practice, we have conducted our study in the province center, and Elazig is a province that is convenient in terms of access. In the study where Grol et $\mathrm{al}^{22}$ researched the priorities of patients in eight European countries (Norway, Sweden, Denmark, United Kingdom, the Netherlands, Germany, Portugal, and Israel), in the first-step health services, the common priorities in the eight countries were found to be "doctor-patient communication and accessibility of the service provider units".

When chronic disease frequency was considered, 72.0\% of the 1,290 patients did not have a known chronic disease, and $28 \%$ had one or more than one chronic disease. The average scores of the patients who had chronic diseases and patients who stated to have physical handicap were higher compared to those who did not have chronic disease and physical handicap, but these differences were not found to be statistically significant either $(P>0.05)$. In a study conducted by Hearnshaw et $\mathrm{al}^{23}$ with 200 patients in each of eight European countries, it was reported that $66.4 \%$ of the patients did not have any chronic disease and that these patients gave higher scores in terms of satisfaction with firststep health services like in our study.

The items that the patients were most satisfied with (which they gave 4 or 5 points) were the questions "How much are you satisfied in terms of that he/she keeps your records" (1,145 patients, $88.8 \%)$, "He/she examines you" $(1,107$ patients, $85.8 \%$ ), and "He/she listens to you" (1,101 patients, $85.4 \%$ ). As understood from these items, the patients were highly satisfied with the fact that the information belonging to them remained secret only between them and their physicians. A contrary situation would certainly affect the patient-physician relationship negatively. The physician's examining and listening to his/her patient was another item that the patients were most satisfied with. In EUROPEP study conducted by Abu Mourad et al in 2007, the questions where satisfaction was highest were "How much are you satisfied in terms of examining you, he/she makes it easy for you to tell your problems to him/her, and he/she gives the information you want about your complaints or disease?"24

Among those who gave one point in our study, the least satisfaction was in the questions "How much are you satisfied in terms of the time you spend in the waiting room" (108 patients, 8.4\%), "You can access your doctor by telephone" (134 patients, 10.4\%), and "He/she assists you to overcome the emotional problems associated with your health condition" (66 patients, 5.1\%). The discomfort felt by individuals about the time they spend in the waiting room and the fact that the physician could not have spared sufficient time to the patient during the visits may be due to the physicians' examining too many patients during the day. 
Physicians focusing on disease-centered care rather than focusing on the patients might have led to their not being interested in the private and emotional states of the individuals. In the study of Kersnik, ${ }^{25}$ among those who gave one point to EROPEP questions, the least satisfaction was in the time you spend in the waiting room with $26 \%$.

The items for which the patients who participated in our study most answered as "not applicable" since they thought that such questions were not applicable to them were the questions "How much are you satisfied in terms of that you can access your doctor by telephone" (19 patients, 1.5\%), "You can access the health center by telephone" (16 patients, $1.2 \%$ ), and "The time you spend in the waiting room" (10 patients, $0.8 \%$ ). The patients in our region did not deem getting appointment and accessing the physician or health center by telephone necessary during application to the family health centers. Although this is thought to be likely to result from the fact that the patients can conveniently access the health centers whenever they wish, the situation which the patients are most dissatisfied with is "the time they spend in the waiting room" might be thought to be associated with this. In a study comparing nine countries in Europe (Denmark, Germany, the Netherlands, Norway, United Kingdom, Belgium, Switzerland, Slovenia, and Spain), the lowest and highest scores to the question "How much are you satisfied in terms of that you can access the health center by telephone?" were given in Denmark and Switzerland, respectively, the lowest and highest scores to the question "How much are you satisfied in terms of that you can access your physician by telephone?" were given in the United Kingdom and Slovenia, respectively, and the lowest and highest scores to the question "How much are you satisfied in terms of the time you spend in the waiting room?" were given in the United Kingdom and Switzerland, respectively.

\section{Conclusion and suggestions}

Conclusion of our study may be summarized as follows:

- It was observed that $43.6 \%$ of the patients included in the study did not have any difficulty in access to the health center, and 29.2\% occasionally had difficulty. When reasons for applying to the family health centers were examined, it was observed that $26.7 \%$ patients applied due to a new complaint and $24.7 \%$ applied for getting prescription.

- When the EUROPEP-TR Patient Satisfaction Survey general average scores were evaluated by the age groups of the patients, no significant difference was found between the age groups (ANOVA $F=1.280, P=0.27$ ). Average score of the male patients was found to be higher than that of female patients $(P<0.001)$. Scores of the patients whose marital status is divorced and widow were higher compared to other groups, but this was not statistically significant $(P=0.08)$.

- Average scores of the patients whose educational status is secondary school was higher compared to other groups $(P=0.01)$. Scores of the patients with children were higher compared to those without children $(P=0.01)$. Scores of the patients whose occupation was farming were higher compared to the other groups of occupation $(P=0.01)$. Scores of the patients whose income was TL 1,001-2,500 were higher compared to other patients $(P<0.001)$. Scores of the patients who stated that they never had difficulty in access were higher compared to others, but this difference was not statistically significant $(P=0.71)$.

- Average scores of the patients who had chronic diseases and patients who stated to have physical handicap were higher compared to those who did not have, but these differences were not found to be statistically significant either $(P>0.05)$. Average score of the patients whose reason of application is medication report was higher compared to other patients, but this difference was not statistically significant $(P=0.44)$.

According to the conclusions obtained from the study, we can make the following suggestions:

- For a quality and effective service provision, the reasons why the dissatisfied segment has a low level of satisfaction with the family medicine practice should be researched, strategies should be developed based on the research results, and continuity in practice should be ensured.

- For enhancing the quality in the first-step health services, patient satisfaction should be measured at regular intervals, and arrangements should be made on the issues leading to dissatisfaction.

\section{Disclosure}

The authors report no conflicts of interest in this work.

\section{References}

1. Cirakli ZL, Sayim F. Examination of the cost benefit, cost effectiveness analysis indicators in the quality management systems in health services at the hospitals. International Congress on Performance and Quality in Health - Book of Proceedings. Ankara; 2009:347-365.

2. Cinar U. Operational Study in Health Systems Ankara. Ankara: Ongun Kardesler Printing House; 1982:22.

3. Eren N, Oztek Z. Health Center Management. 6th ed. Ankara: Palme Publications; 1993. 
4. Unalan P. Definition and basic principles of family medicine. Republic of Turkey Ministry of Health Course Notes for Family Doctors. 1st ed. Ankara; 2004:11-15.

5. Carr-Hill AR. The measurement of patient satisfaction. J Public Health Med. 1992;14(3):236-249.

6. Ozer M, Sahin B, Cetin M, Demir C. Examination of the factors affecting job satisfaction levels of the physicians working at three military hospitals located in the province of Ankara. Hacett J Health Admin. 2005;8(1):31-49.

7. Ozer A, Cakil E. The factors affecting patient satisfaction in health services. Med Res J. 2007;5(3):140-143.

8. Grol R, Wensing M. Patients Evaluate General/Family Practice: The EUROPEP Instrument. Nijmegen: Center for Quality of Care Research; 2000.

9. Wensing M, Jung HP, Mainz J, Olesen F, Grol R. A systematic review of the literature on patient priorities for general practice care. Part 1: description of the research domain. Soc Sci Med. 1998;47(10):1573-1588.

10. Uz HM, Ozbakir DI, Ergin C. Patient Satisfaction in First Step Health Services: A Field Study. Ankara: Publication of Haberal Education Foundation; 1997:113-118.

11. Besparmak A, Sevig U. Use of first step health services in the region of Argincik health center in Kayseri province center and the factors affecting use. Health Sci J. 2005;14:1-6.

12. Ramsay J, Camphell JL, Schroter S, Green J, Roland M. The General Practice Assessment Survey (GPAS): tests of data quality and measurement properties. Fam Pract. 2000;17(5):372-379.

13. Erdem R, Rahman S, Avc1 L, et al. The effect of patient satisfaction on patient loyalty. Erciyes University. J Fac Econ Admin Sci. 2008; 31:95-110.

14. Deveci ES, Ogeturk A, Ozan Tevfik A, Tokdem M, Acik Y. Awareness of applicants of a first step health institution about patient rights. Clin Turkey J Med Ethics. 2005;13:174-178.

15. Unalan D, Ozturk A, Tolga Y, et al. Satisfaction in adult patients registered with the social security institution, who receive polyclinic service from Kayseri state hospital. Firat Health Serv J. 2008;3(8):85-98.
16. Pearsman W, Jacobs N, De Maeseneer J, Seuntjens L. The Flemish version of a new European standardised outcome instrument for measuring patients' assessment of the quality of care in general practice. Arch Public Health. 2002;60:39-58.

17. Tukel B, Acuner AM, Onder ÖR, Uzgul A. Satisfaction of the patients hospitalized at Ankara University Ibn-i Sina Hospital. Ankara University. Fac Med J. 2004;57(4):205-214.

18. Turgu S. Research of patient satisfaction at the first step health institutions in Edirne province center and its relationship with the physicians' job satisfaction, Thesis, Trakya University Faculty of Medicine, Edirne, 2012.

19. Pala T. Evaluation of the Health Services by the Community of Inonu Health Center Region and Employees of Narlidere Health Group Presidency. Izmir; 1997. Available from: http://tez2.yok.gov.tr/. Accessed November 8, 2013.

20. Senol V, Cetinkaya F, Balci E. Factors associated with health services utilization by the general population in the Center of Kayseri, Turkey. Clin Turkey J Med Sci. 2010;30(2):721-730.

21. Ercan I, Ediz B, Kan I. Examination of satisfaction of patients with health services by their socio-economic statuses. Inonu University. Fac Med J. 2004;11(3):161-167.

22. Grol R, Wensing M, Mainza J, et al. Patients' priorities with respect to general practice care: an international comparison. Fam Pract. 1999;16(1):4-11.

23. Hearnshaw H, Wensing M, Grol R, et al. The effects of interactions between patient characteristics on patients' opinions of general practice care in eight European countries. Prim Health Care Res Dev. 2002;3:231-237.

24. Abu Mourad T, Shashaa S, Markaki A, Alegakis A, Lionis C, Philalithis A. An evaluation of patients' opinions of primary care physicians: the use of EUROPEP in Gaza Strip-Palestine. J Med Syst. 2007;31:497-503.

25. Kersnik J. An evaluation of patient satisfaction with family practice care in Slovenia. Int J Qual Health Care. 2000;12(2):143-147.
Patient Preference and Adherence

\section{Publish your work in this journal}

Patient Preference and Adherence is an international, peer-reviewed, open access journal that focuses on the growing importance of patient preference and adherence throughout the therapeutic continuum. Patient satisfaction, acceptability, quality of life, compliance, persistence and their role in developing new therapeutic modalities and compounds to optimize

\section{Dovepress}

clinical outcomes for existing disease states are major areas of interest for the journal. This journal has been accepted for indexing on PubMed Central. The manuscript management system is completely online and includes a very quick and fair peer-review system, which is all easy to use. Visit http://www. dovepress.com/testimonials.php to read real quotes from published authors. 